\title{
IMPACTOS AMBIENTAIS CAUSADOS PELA UTILIZAÇÃO DE TRILHAS NA RESERVA ECOLÓGICA DA JOATINGA, PARATY, RJ
}

\section{Luana de Almeida Rangel ${ }^{1}$}

Márcia Barbosa Martins ${ }^{2}$

Antonio José Teixeira Guerra ${ }^{3}$

\section{Resumo}

As Unidades de Conservação (UCs) são áreas naturais protegidas onde se prevê o uso público (turismo, educação, pesquisas, etc), mas este uso pode gerar diversos impactos ambientais. No caso das Reservas Biológicas (REBIO), unidades mais restritivas, são proibidas alterações na paisagem permitindo-se apenas as pesquisas e a recuperação ambiental. Muitas dessas UCs se localizam em áreas de difícil acesso e as trilhas são os caminhos mais utilizados. Elas possibilitam a aproximação dos visitantes ao ambiente natural e podem conduzi-los a um atrativo específico, tornando possível seu entretenimento ou educação por meio de sinalizações ou de outros recursos interpretativos. É comum, nas áreas das trilhas, deparar-se com ambientes degradados, com a presença de lixo, pichação, erosão, entre outros. Nesse sentido, o presente trabalho pesquisou o impacto em duas trilhas localizadas ao sul da Reserva Ecológica da Joatinga, município de Paraty, Rio de Janeiro: a trilha Praia do Sono - Praia de Antigos e a trilha Enseada de Ponta Negra - Praia de Galhetas. Foi empregada uma metodologia perceptiva proposta por Cole (1987) e a metodologia proposta por Leung e Marion (1996). As características das trilhas analisadas foram: tamanho, presença de degraus, raízes e blocos rochosos, presença de lixo, áreas queimadas e outros tipos de degradação. Verificou-se que elas estão sofrendo com o impacto do turismo, já que foi possível observar áreas degradadas no entorno da trilha.

Palavras-chave: Áreas protegidas; processos erosivos; degradação ambiental.

\section{Abstract}

Conservation Units (CUs) are natural protected areas and used also by tourism, which causes many environmental impacts. One category of protected area is the Ecological Reserve, where it is forbidden for humans to make changes in the landscape. Since many of these PAs are in difficult access areas, the trails are the most used way within these protected areas. The trails allow visitors to approach the natural environment, and can lead them to a specific attractive, making it possible its entertainment and education through signage or other interpretative resources. It is common in trails to come across degraded environments, with the presence of garbage, graffiti, erosion, among others. Therefore, the present study aims, from the perceptive methodology proposed by Cole (1987) and the methodology proposed by Leung and Marion (1996), to assess the impact of two trails located in the south of the Ecological Reserve of Joatinga in the municipality of Paraty, Rio de Janeiro State: Sono -

\footnotetext{
${ }^{1}$ Mestranda em Geografia pela Universidade Federal do Rio de Janeiro, Integrante do Lagesolos, Departamento de Geografia - E-mail: luarangel@ufrj.br

${ }^{2}$ Doutoranda em Meio Ambiente pela Universidade do Estado do Rio de Janeiro, Pesquisadora do Lagesolos E-mail: marciabm@gmail.com

${ }^{3}$ Professor Titular do Departamento de Geografia da Universidade Federal do Rio de Janeiro - Coordenador do Lagesolos - E-mail: antoniotguerra@gmail.com
} 
Antigos trail and Ponta Negra - Galhetas trail. We have analyzed the trail characteristics, such as trail size, presence of steps, roots and rocks, presence of garbage, burned areas and other types of degradation. It was found that the trails are suffering with the impact of tourism, since it is possible to observe degraded areas surrounding the trail.

Keywords: Protected areas; erosion; environmental degradation.

\section{Introdução}

A criação de Unidades de Conservação (UCs) está se tornando cada vez mais frequente já que o constante desenvolvimento econômico da sociedade eleva a preocupação com a proteção de áreas silvestres e recursos naturais. Uma UC é um espaço territorial instituído pelo poder público com a finalidade específica de conservar as características naturais relevantes presentes na área, podendo ser de Proteção Integral (PI) ou de Uso Sustentável (US), segundo a Lei Federal 9.985 que estabeleceu o Sistema Nacional de Unidades de Conservação da Natureza - SNUC (BRASIL, 2000).

O conceito de UC agrega a função de instrumento de proteção dos recursos naturais e da gestão territorial, ou seja, tentando garantir a proteção e uso adequado dos bens que a sociedade pode obter dos ecossistemas. Vê-se, portanto, que hoje as UCs ultrapassam a lógica da proteção isolada de fragmentos de habitats, para uma estratégia de proteção do todo, buscando reorientar opções econômicas e políticas sobre o acesso e uso dos recursos naturais.

Antes da Lei do SNUC (2000), havia uma categoria de área protegida chamada de Reserva Ecológica, mas esta deixou de existir, permanecendo apenas as Estações Ecológicas e Reservas Biológicas. Conforme estabelecido pela própria Lei, haverá necessidade de reclassificação (ou recategorização) das antigas nomenclaturas ao novo sistema. Entretanto, nem todas as denominações foram modificadas pelos governos, como determina a lei. Um desses casos é o da Reserva Ecológica da Joatinga/RJ, UC estadual e objeto deste estudo.

Considerando que algumas UCs estão em áreas de difícil acesso, as trilhas (caminhos, rastros ou picadas, segundo CASTILHO, 2006), são as principais estratégias de circulação em seu interior. Elas possuem diferentes formas, comprimentos e larguras, e possibilitam a aproximação dos visitantes ao ambiente natural, podendo conduzi-los a um atrativo específico, tornando possível seu entretenimento ou educação por meio de sinalizações ou de outros recursos interpretativos (NEIMAN et al., 2009). Andrade (2008) destaca que a principal função das trilhas é suprir a necessidade de deslocamento.

O estudo dos impactos que a circulação de pessoas causa nas trilhas em áreas protegidas, vem crescendo bastante ultimamente. A partir disso, surge uma questão levantada por Kroeff (2010, p. 11) ao afirmar que as trilhas podem ser consideradas como forças de tensão, podendo dificultar o alcance de alguns preceitos das UCs no que se refere à preservação da biodiversidade dos ecossistemas naturais e sua restauração, quando geram degradação. Há de se destacar que as trilhas também contribuem para a educação ambiental aproximando pessoas dos atributos naturais das áreas protegidas e o problema acontece quando não existem medidas de gestão do uso, monitoramento e recuperação. 
O presente trabalho teve como objetivo principal avaliar os impactos em duas trilhas da Reserva Ecológica da Joatinga, localizadas em Paraty: a trilha Praia do Sono - Praia de Antigos e a trilha Enseada de Ponta Negra - Praia de Galhetas. Para atender os objetivos, foram utilizadas as metodologias propostas por Cole (1987) e Leung e Marion (1996).

\section{Áreas de Proteção Integral}

As Áreas de Proteção Integral (API) têm como objetivo preservar a natureza sendo admitido apenas o uso indireto dos seus recursos naturais (BRASIL, 2000). Compreende as seguintes categorias: Estação Ecológica, Reserva Biológica, Parque Nacional, Monumento Natural e Refúgio da Vida Silvestre. Os objetivos das Reservas Biológicas estão descritos na no Artigo $10^{\circ}$ da lei do SNUC (BRASIL, 2000):

Art. 10. A Reserva Biológica tem como objetivo a preservação integral da biota e demais atributos naturais existentes em seus limites, sem interferência humana direta ou modificações ambientais, excetuando-se as medidas de recuperação de seus ecossistemas alterados e as ações de manejo necessárias para recuperar e preservar o equilíbrio natural, a diversidade biológica e os processos ecológicos naturais.

$\S 2^{\mathrm{o}}$ É proibida a visitação pública, exceto aquela com objetivo educacional, de acordo com regulamento específico.

Com base neste Artigo, as REBIO's não podem ter uso turístico em suas trilhas e estas serviriam apenas para o acesso eventual da fiscalização da UC, de pesquisadores autorizados, de grupos credenciados em ações de recuperação ambiental e/ou educativas.

Segundo Santos (2008), as Áreas de Proteção Integral podem ter em seu entorno Unidades de Uso Sustentável (Áreas de Proteção Ambiental- APA's; Áreas de Relevante Interesse Ecológico - ARIE's, entre outras) que vão, juntamente com zonas de amortecimento (ZA's) e corredores ecológicos, compor instrumentos legais de proteção das, API's. Vieira (2011, p. 41) destaca que muitas APA's atuam como áreas de amortecimento de API's nas regiões metropolitanas. Essa tentativa nem sempre garante a proteção legal em função de pressões de grupos da sociedade civil com interesses conflitantes aos objetivos das APAs.

No caso da Reserva Ecológica da Joatinga/RJ existe a necessidade de recategorização, processo que já está em andamento. Ela possui como zona de amortecimento a Área de Proteção Ambiental do Cairuçu, criada pelo Decreto Federal no 89.242, de 27/12/1983, sob a responsabilidade do ICMBio.

\section{Os impactos das trilhas}

Presume-se que a grande quantidade de estudos sobre trilhas, tanto internacionais como nacionais, seja decorrente da controvérsia que elas causam em UCs, pois seu uso aproxima pessoas das áreas silvestres, mas também podem deflagrar diversos impactos. Para Lechner (2006) as trilhas e caminhos são, provavelmente, as rotas de viagem mais disseminadas pelo mundo. Em áreas naturais protegidas, as trilhas podes ser o único acesso 
disponível. Em todos os estudos feitos sobre trilhas, percebe-se a procura cada vez maior por áreas naturais, o que ameaça a conservação dessas e preconiza a necessidade de se combater ou atenuar os impactos causados pelo seu uso e por seus usuários (KROEFF, 2010).

Andrade (1997) destaca que a principal função das trilhas é suprir a necessidade de deslocamento. Passold (2002) enfatiza que além dessa função básica, a trilha motiva oportunidades de recreação aos visitantes, tornando-se um novo meio de contato com a natureza, além de contribuir com a proteção dos recursos naturais, incorporando uma nova característica e passando a ter um significado próprio.

Sánchez (2006) reitera que quando negativo, o impacto ambiental causa a degradação ambiental, ou seja, a perda ou deterioração da qualidade ambiental, a redução das condições naturais ou do estado de um ambiente. Os impactos da erosão do solo geram condições indesejáveis nas trilhas que podem afetar negativamente a experiência do usuário. Trilhas com acumulação de água e/ou profundamente erodidas podem gerar diversos problemas, como a diminuição da sua própria utilidade funcional (JEWELL; HAMMITT, 2000).

De acordo com Takahashi (1998), o pisoteio das trilhas compacta os solos alterando sua porosidade em razão da redução do volume de macroporos. Este aumento na compactação eleva a resistência mecânica do solo à penetração de raízes e à infiltração de água, reduzindo a regeneração natural. Magro (1999) afirma que quando o pisoteio é frequente, o solo é compactado provocando a selagem do mesmo e aumentando sua susceptibilidade à erosão e perda de matéria orgânica.

\section{A Reserva Ecológica da Joatinga (REJ)}

A REJ foi criada pelo governo do estado do Rio de Janeiro através da Lei Estadual $\mathrm{n}^{\circ}$ 1.859 de 01/10/1991 e pelo Decreto n 17.981 de 30/10/1992. Ela está localizada no sul do estado do Rio de Janeiro, no município de Paraty (Figura 01). O decreto define os limites da Reserva da seguinte forma: de um lado, pelo Saco de Mamanguá, de outro e pela frente, pelo mar aberto e, pelos fundos, por uma linha reta imaginária que, partindo do ponto conhecido como Cachoeira do Cocal (no lado do Canto Bravo da Praia do Sono), alcança o local conhecido como Porto do Sono - ao fundo do Mamanguá (RIO DE JANEIRO, 1992).

Os limites da REJ englobam os locais onde a comunidade caiçara mantinha suas roças, restringindo-as e proibindo algumas práticas tradicionais utilizadas, como a caça, que era de fundamental importância quando havia falta de pescado. A área aproximada da REJ é de 8.000 hectares e os núcleos de povoamentos da REJ são: Praia do Sono, Ponta Negra, Praia Grande do Pouso da Cajaíba, Ponta da Joatinga, Cairuçu das Pedras, Martins de Sá e Mamanguá (ICMBIO, 2008).

De acordo com o Mapa de Vegetação do Brasil (IBGE, 2004), a vegetação florestal apresenta as subclassificações de Florestas Ombrófila Densa Montana e Floresta Ombrófila Densa Submontana. Com elevada biodiversidade, se destaca a exuberância da mata higrófila nas encostas e nos vales, a mata de restinga e os manguezais do fundo do Saco do Mamanguá. As vertentes apresentam afloramentos rochosos cobertos por flora característica, constituída principalmente por gramíneas (INEA, 2012). 


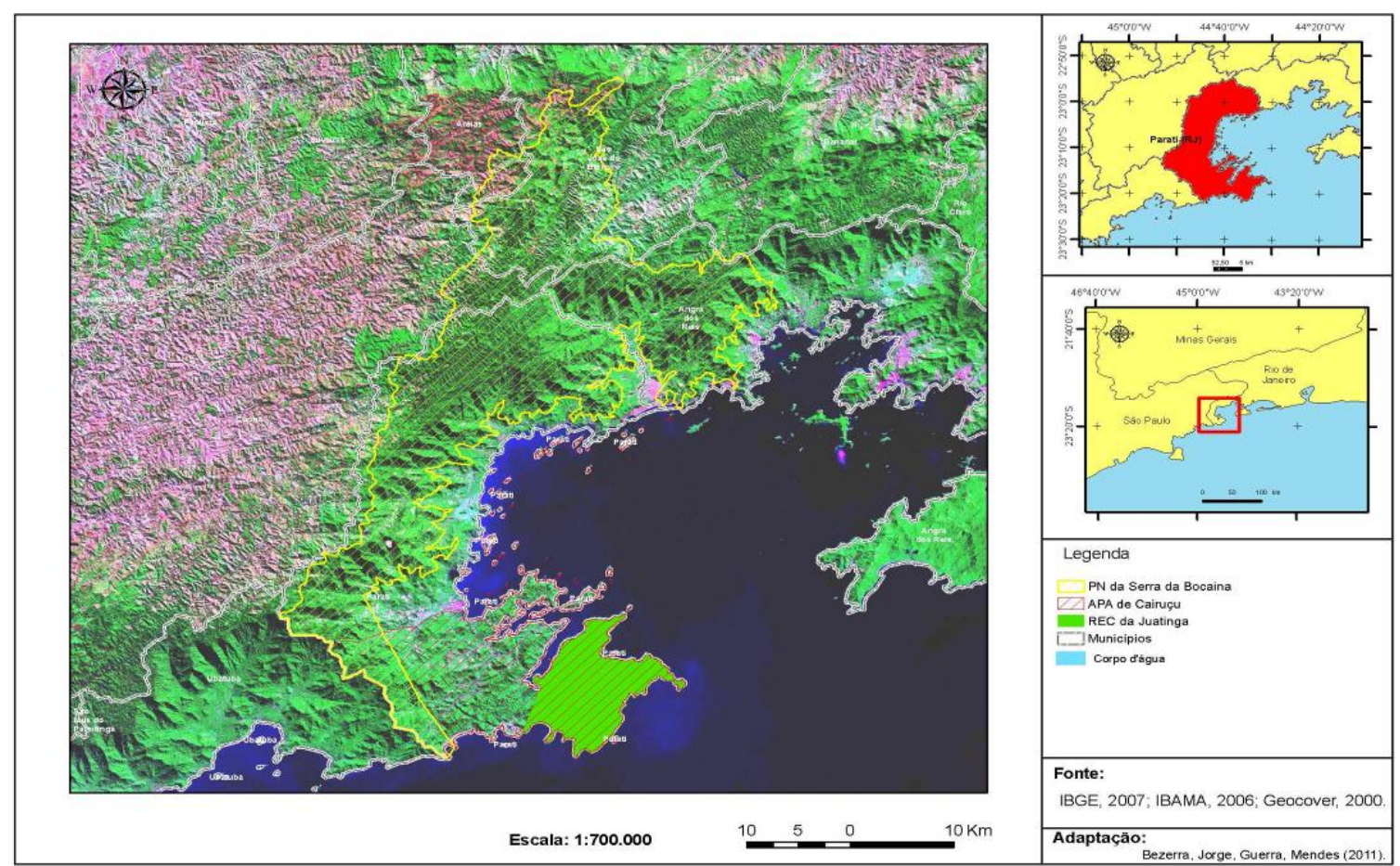

Figura 01. Localização da Reserva Ecológica da Joatinga. Fonte: Bezerra et. al. (2011)

A reserva está situada na vertente oceânica da Serra do Mar. Possui relevo bastante acidentado, variando desde ondulado, montanhoso e escarpado, com altitudes que vão do nível do mar até $1.070 \mathrm{~m}$, no Pico do Cairuçu. O tipo de clima é super-úmido, com pouco ou nenhum déficit hídrico.

Os solos que ocorrem na parte movimentada do relevo são, em geral, de elevada acidez e com indicativos de baixa fertilidade. Nas áreas planas, em pequenas várzeas, os solos são também ácidos, hidromórficos, argilosos e muito argilosos sendo influenciados pelo nível elevado do lençol freático (MARQUES, 1997). A Figura 02 apresenta a localização das duas trilhas estudadas.

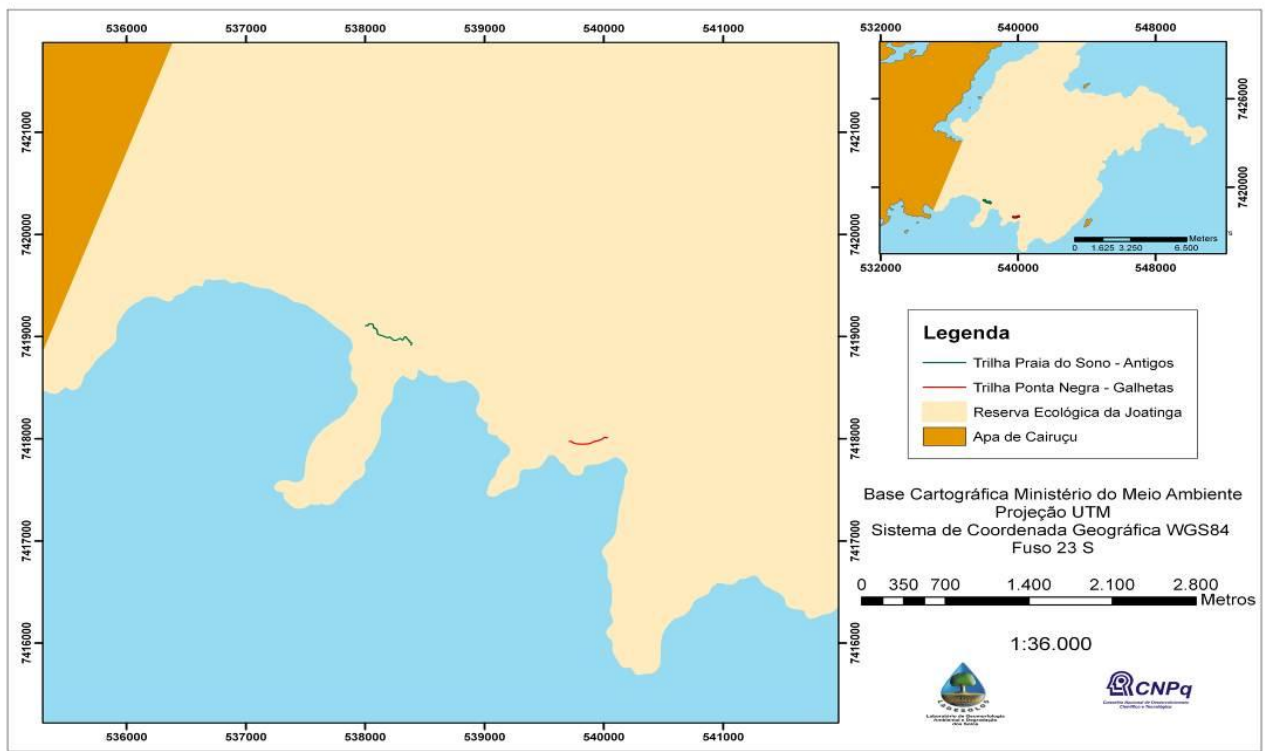

Figura 02. Localização das trilhas Praia do Sono - Praia de Antigos e da Ponta Negra Galhetas. Elaboração própria. 
Buscou-se, através da pesquisa descritiva - onde parâmetros de solo e vegetação são mensurados e correlacionados com as características de uso - avaliar as condições das trilhas (COLE, 1987). Além disso, foram usados indicadores como largura e erosão, existência de múltiplas trilhas e a compactação do solo (LEUNG; MARION, 1996).

\section{Resultados e discussão}

\section{a) Trilha Praia do Sono - Praia de Antigos}

A praia do Sono possui, aproximadamente, 54 famílias residentes (ICMBIO, 2004). A pesca e o turismo são as principais atividades da região, portanto, a trilha que se inicia na praia do Sono e vai até a praia de Antigos é bastante utilizada por praticantes de ecoturismo. A trilha possui extensão de aproximadamente 600 metros. Essa trilha encontra-se em uma encosta com declividade de aproximadamente $27^{\circ}$, evidenciando diversas feições erosivas provocadas pela concentração de água (Figura 03). A água da chuva que carrega os sedimentos oriundos da trilha pode provocar assoreamento de um córrego que deságua no canto esquerdo da praia.

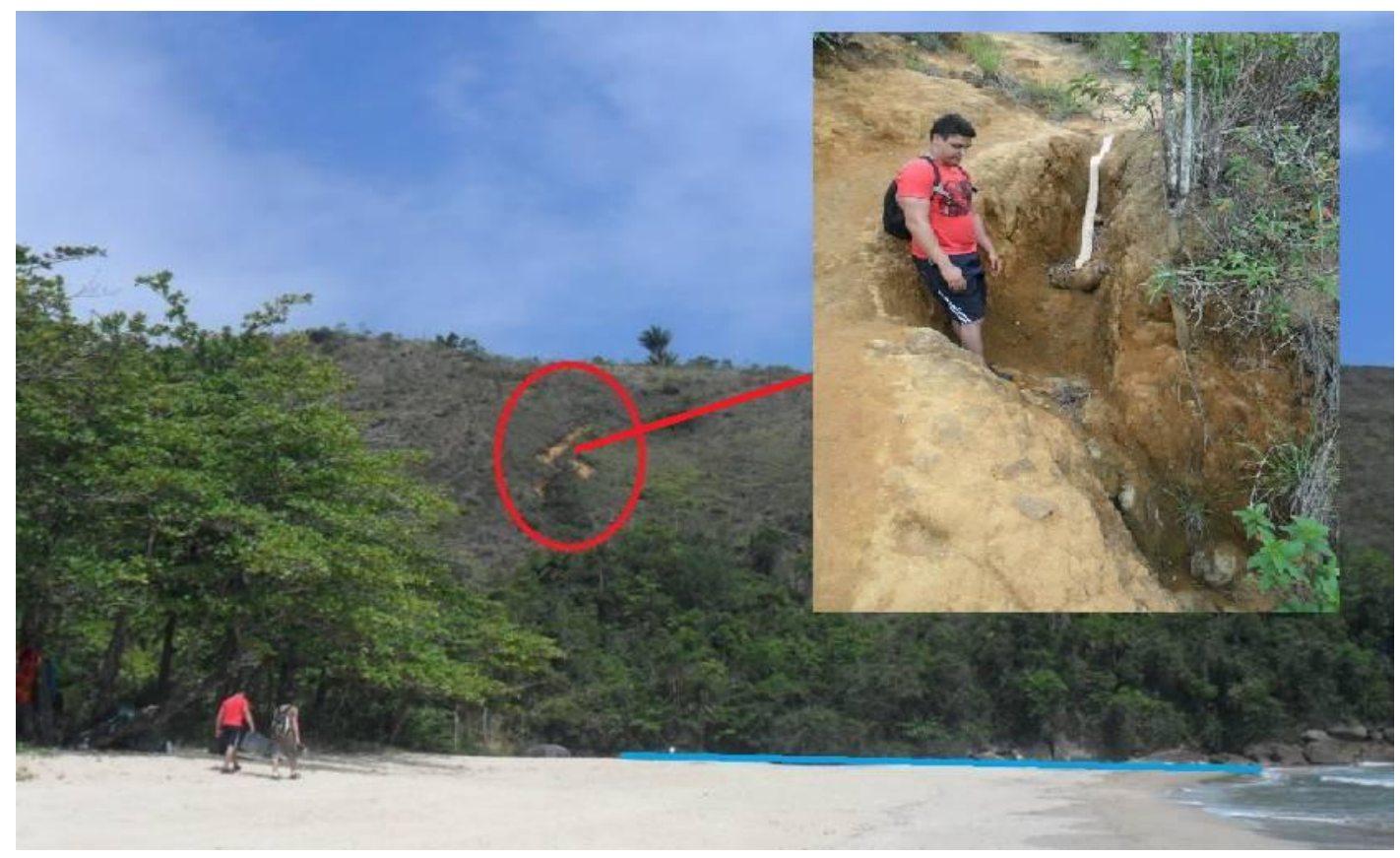

Figura 03. Trilha Praia do Sono - Antigos (em vermelho) e o Córrego do Sono (em azul) que recebe sedimentos da trilha quando chove (à esquerda) e feição erosiva provocada por concentração de fluxo de água (à direita). Acervo: L. A. RANGEL, 2012.

Cole (1993) destaca que o pisoteio frequente provoca a perda do material orgânico dos primeiros centímetros do solo, causando assim sua compactação. O pisoteio causa o corte, a quebra e a exposição de raízes da vegetação, sendo assim, as plantas que estão nas trilhas tendem a reduzir de tamanho, podendo vir a morrer.

Seguindo o que foi proposto por Leung e Marion (1996), observou-se que a trilha, até o ponto mais alto da encosta, apresenta raízes e blocos rochosos expostos, média acumulação 
de água, presença de degraus - o que exemplifica erosão de uma trilha - e a largura varia entre 2 e $3 \mathrm{~m}$.

Conclui-se que a trilha está bastante degradada até o ponto mais alto da encosta, onde a vegetação começa a ficar mais densa, a presença de feições erosivas não é mais tão evidente e o tamanho da diminuiu, variando de 1,0 a $1,5 \mathrm{~m}$.

\section{b) A trilha Enseada de Ponta Negra - Praia de Galhetas}

A enseada de Ponta Negra possui aproximadamente 25 famílias residentes (ICMBIO, 2004). O acesso à enseada só é possível através da trilha que se inicia na vila Oratório e passa pela praia do Sono, praia de Antigos, praia de Antiguinhos, praia de Galhetas e finalmente chega à enseada de Ponta Negra. Também é possível chegar à enseada por embarcações. A trilha que se inicia na enseada e vai até a praia de Galhetas tem aproximadamente 350 metros de extensão.

A vegetação predominante na trilha é arbustiva e espaçada. A área de pisoteio possui largura que varia de 0,84 a 1,60 m. Já a largura, que segundo Cole (1993) está relacionada ao tamanho total da trilha, que inclui a área pisoteada e a área não-pisoteada, varia de 2,35 metros a 1,16 m (Figura 04).

Os principais fatores que influenciam a intensidade do impacto são frequência do uso, tipo e comportamento do usuário, estação climática e condições ambientais (COLE, 1981, 1987). Cole (2004) acrescenta que logo após a abertura de uma trilha, pequenos aumentos na frequência do uso causam intensificação dos impactos, no entanto, o nível de degradação decresce com o aumento do uso.

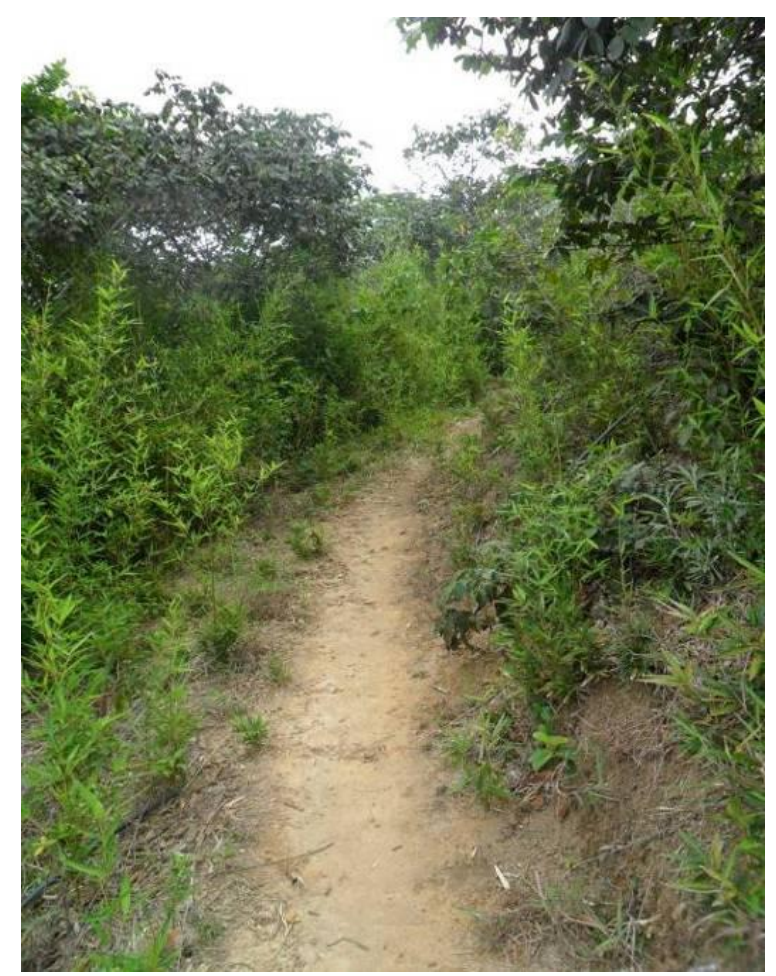

Figura 04. Trilha Ponta Negra - Galhetas onde se observa a vegetação arbustiva. Acervo: L. A. RANGEL, 2012. 
Kroeff (2010) destaca que ao longo das trilhas é comum deparar-se com ambientes degradados, presença de lixo, pichações, queimadas, entre outros, contradizendo os objetivos de um ambiente natural de conservação. É importante destacar que os visitantes, muitas vezes, são responsáveis por essa degradação, já que, eles próprios jogam lixo, picham e geram outros impactos. Na trilha Ponta-Negra - Galhetas a presença de lixo é constante, além disso, observam-se diversas encostas com áreas de queimadas recentes conforme apresentado na Figura 05 (a e b).
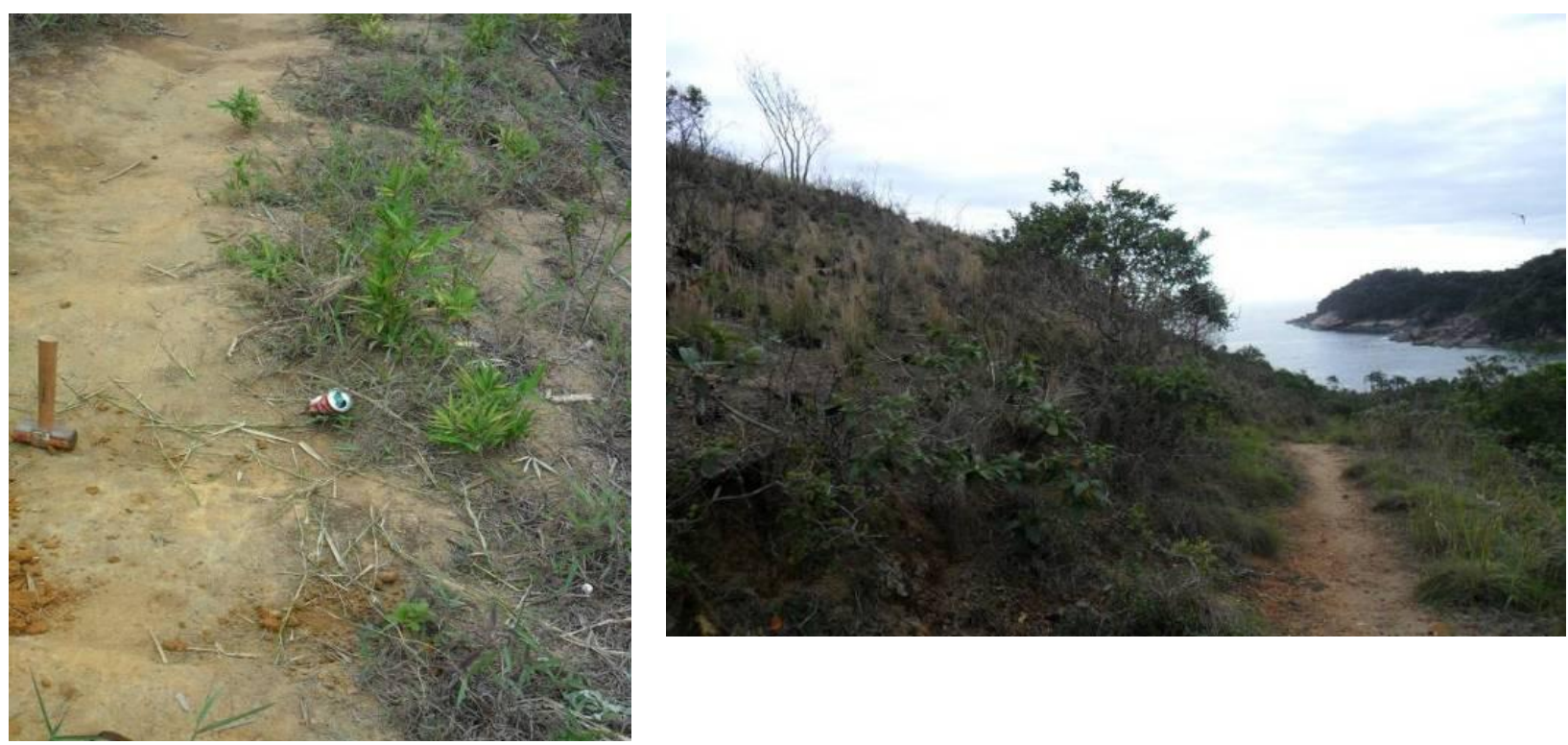

Figura 05. a) Presença de lixo na trilha (esquerda); b) encosta com área queimada (direita).

Acervo: L. A. RANGEL, 2012.

Outros impactos são perceptíveis, como a presença de degraus, variando entre 10 e 30 $\mathrm{cm}$, que são caminhos preferenciais podendo causar maior turbulência de fluxo hídrico e aumentam com o frequente pisoteio (Figura 06).

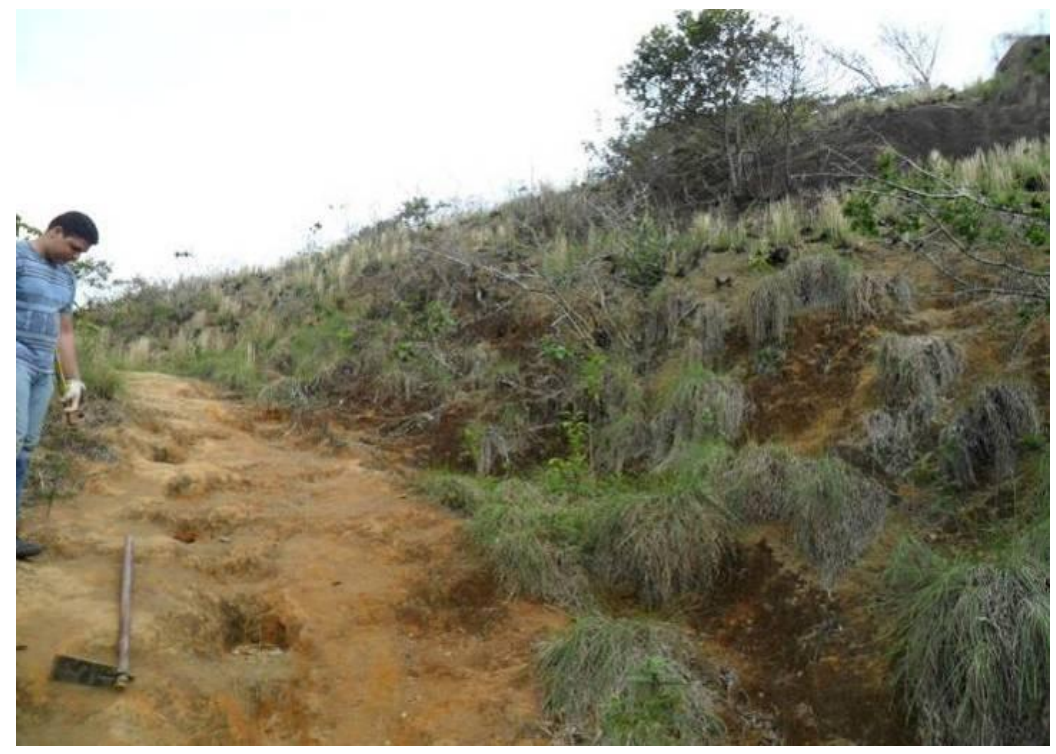

Figura 06. Presença de degraus na trilha. Acervo: L. A. RANGEL, 2012. 


\section{Conclusões}

Por estarem inseridas em uma Reserva Ecológica, as trilhas Praia do Sono - Antigos e Ponta Negra - Galhetas deveriam ser menos utilizadas, já que a sua intensa utilização está em desacordo com a proposta de uma Reserva. São observados diversos processos erosivos, principalmente na primeira trilha, onde as feições erosivas estão bem desenvolvidas e a cada evento chuvoso se ampliam. Observam-se desde degraus até ravinas bem desenvolvidas que além de prejudicar a dinâmica do solo e o ambiente como um todo, podem provocar acidentes nos usuários.

A recategorização da UC adequando-a ao SNUC já foi iniciado, mas há necessidade de acelerar o processo para se tentar diminuir os impactos da utilização da área da reserva. Essa discussão vem gerando diversos conflitos entre os moradores locais, administradores da REJ, administradores da APA de Cairuçu (que se sobrepõe a reserva) e o município de Paraty, pois tornaria a utilização mais restritiva limitando o turismo e podendo influenciar também na atividade pesqueira tradicional.

Cole (2004) ressalta que toda trilha sempre causa impactos e, independente do uso, cabe aos gestores avaliar sua magnitude e como o ambiente irá tolerar. Neste sentido, é importante refletir sobre o que foi levantado no início do trabalho: "se as trilhas são consideradas forças de tensão que dificultam a preservação proposta com a criação de UCs, é preciso pensar em uma forma de manejo que seja efetiva e consiga diminuir os impactos que seu uso pode causar". Além disso, é fundamental conscientizar os turistas e demais usuários, no sentido de promover a adoção de condutas adequadas e menos impactantes, pois como foi constatado, os próprios usuários deixam lixo, fazem pichações e fogueiras no entorno das trilhas.

Ademais, foi observado que a administração da REJ não tem conseguido manter eficientemente as atividades de manejo e fiscalização, pontos fundamentais para a preservação da área. Uma alternativa seria que os próprios moradores auxiliassem na fiscalização, o que facilitaria a manutenção do ambiente natural. Isso, entretanto, requer condições e competência administrativa para lidar com os conflitos existentes e, ao mesmo tempo, manter a integridade da área.

\section{Agradecimentos}

Ao $\mathrm{CNPq}$ pelo financiamento do projeto "Diagnóstico de danos ambientais em unidades de conservação: Parque Estadual da Serra do Mar (Núcleo Picinguaba) e Parque Nacional da Serra da Bocaina (Área de Proteção Ambiental do Cairuçu) e Reserva Ecológica da Joatinga", ao qual está ligado esse trabalho. À FAPERJ pelo apoio financeiro através do projeto "Diagnóstico de danos ambientais em unidades de conservação: Parque Nacional da Serra da Bocaina (Área de Proteção Ambiental do Cairuçu) e Reserva Ecológica da Joatinga". 


\section{Referências bibliográficas}

ANDRADE, J. V. Turismo: Fundamentos e dimensões. São Paulo: Ed. Ática, 2008.

BRASIL. LEI N. ${ }^{\circ} 9.985$, de 18 de julho de 2000. Criação do Sistema Nacional de Unidades de Conservação (SNUC). Disponível em: < http://www.planalto.gov.br/ccivil_03/leis/19985.htm >. Acesso em: 13 jul. 2012.

CASTILHO, V. C. da. Propostas de Manejo e Planejamento Ambiental de Trilhas Ecoturísticas: Um Estudo no Maciço da Pedra Branca - Município do Rio de Janeiro (RJ). 2006. 325 f. Tese (Doutorado em Geografia)- Instituto de Geociências, Universidade Federal do Rio de Janeiro, Rio de Janeiro, 2006.

COLE, D.N. Research on soil and vegetation in wilderness: a state-of-knowledge review. In: LUCAS, R.C. Proceedings. National Wilderness Research Conference: Issues, State-ofknowledge, Future Directions. General Technical Report INT-220. Ogden, Utah : U.S. Department of Agriculture, Forest Service. Intermountain Research Station, 1987. p. 135177.

\section{Changes on trails in the Selway-Bitterroot Wilderness, Montana, 1978-89.}

Research Paper INT-450. Ogden, Utah: U.S. Department of Agriculture, Forest Service, Intermountain Research Station, 1991. 5 p.

Minimizing Conflict between Recreation and Nature Conservation. In: SMITH, D.S.; HELLMUND, P.C. (Org). Ecology of Greenways: Design and Function of Linear Conservation Areas. Minneapolis, M. : Univ. of Minnesota Press, p. 105-122, 1993.

Impacts of Hiking and Camping on Soils and Vegetation: A Review. In:

BUCKLEY, R. Environmental impacts of ecotourism. Queensland, Australia:

International Centre for Ecotourism Research. Griffith University, 2004.

IBGE. Produção da Extração Vegetal e da Silvicultura. Rio de Janeiro, v. 20, p. 1-50, 2004.

ICMBio. Plano de Manejo Reserva Ecológica da União. Disponível em: < http://www.icmbio.gov.br/portal/images/stories/imgs-unidades-coservacao/ENCARTE\%201rebio.pdf >. Acesso em: 23 dez. 2012.

INSTITUTO ESTADUAL DO AMBIENTE. Disponível em: < http://www.inea.rj.gov.br/index/index.asp >. Acesso em: 20 nov. 2012.

JEWELL, M. C.; HAMMITT, W. E. Assessing Soil Erosion on Trails: A Comparison of Techniques. In: USDA Forest Service Proceedings RMRS. v. 5., p. 133-140, 2000.

KROEFF, L. L. Contribuição metodológica ao planejamento de trilhas ecoturísticas no Parque Nacional da Serra dos Órgãos (PARNASO), RJ. 2010. 199 f. Dissertação (Mestrado em Geografia)- Instituto de Geociências, Universidade Federal do Rio de Janeiro, Rio de Janeiro, 2010.

LECHNER, L. Planejamento, implantação e manejo de trilhas em unidades de conservação. Cadernos de Conservação, Curitiba, Fundação O Boticário de Proteção à Natureza, ano 3, n. 3, jun. 2006.

LEUNG, Y. F.; MARION, J. L. Trail degradation as influenced by environmental factors: A state-of-knowledge review. Journal of Soil and Water Conservation, v. 51, n. 2, p. 130136, 1996. 
MARQUES, M. C. M. Mapeamento da cobertura vegetal e listagem das espécies ocorrente na área de proteção ambiental de Cairuçu, município de Paraty, RJ. Rio de Janeiro: Fundação Nacional Jardim Botânico, 1997. 96 p.

NEIMAN, Z.; CARDOSO-LEITE, E.; PODADERA, D.S. Planejamento e implantação participativos de programas de interpretação em trilhas na "RPPN Paiol Maria", Vale do Ribeira (SP). In: Revista Brasileira de Ecoturismo, São Paulo, v. 2, n. 1, p.11-34, 2009.

PASSOLD, A. J. Seleção de indicadores para o monitoramento do uso público em áreas naturais. 2002. Dissertação (Mestrado em Agricultura) - Escola Superior de Agricultura Luiz e Queiroz, Universidade de São Paulo, Piracicaba, 2002

RIO DE JANEIRO. Decreto N. ${ }^{\circ} 17.981$, de 30 de outubro de 1992. Criação da Reserva Ecológica de Joatinga, no município de Paraty, e dá outras providências. Disponível em: < http://www.ief.rj.gov.br >. Acesso em: 3 dez. 2012.

SÁNCHEZ, L. E. Avaliação de impacto ambiental: conceitos e métodos. São Paulo: Oficina de Textos, 2006.

SANTOS, A. A. B. Conselhos gestores de Unidades de Conservação. 2008. 186 f. Tese (Doutorado em Ciências Florestais)- Departamento de Engenharia Florestal, Universidade de Brasília, Brasília, 2008.

ICMBIO. Plano de Manejo da APA de Cairuçu. 2004. Disponível em: < http://www.icmbio.gov.br/portal/biodiversidade/unidades-de-conservacao/biomasbrasileiros/marinho/unidades-de-conservacao-marinho/2240-apa-de-cairucu.html > . Acesso em: 08 jul. 2012.

TAKAHASHI, L. Y. Caracterização dos visitantes, suas preferências e percepções e avaliação dos impactos da visitação pública em duas unidades de conservação do Estado do Paraná. 1998. 129 f. Tese (Doutorado em Engenharia Florestal) - Universidade Federal do Paraná, Curitiba. 1998.

VIEIRA, A. J. N. L. Processos de Governança em Áreas de Proteção Ambiental: Análise a partir do Conselho Gestor da APA Itupararanga - SP. Dissertação (Mestrado em Geografia Física)- Departamento de Geografia, Universidade de São Paulo, São Paulo, 2011. 